\title{
ENTREVISTA A ENRIQUE DUSSEL
}

Patricia Alejandro

Universidad Nacional de Rosario

(Argentina)

patriciaalejandro@yahoo.com.ar

Damián Ciappina

Universidad Nacional de Rosario

(Argentina)

damiancac@hotmail.com

\section{Agradecimientos}

En su visita a la Facultad de Humanidades y Artes de la Universidad Nacional de Rosario, en el marco del cumplimiento de los 70 años de esta Casa de Estudios y a propósito de que la Facultad de Humanidades y Artes lo declarara doctor honoris causa, a solicitud de la Escuela de Filosofía, el 28 de octubre del presente año, el filósofo argentino Enrique Dussel, accedió a la presente entrevista en la ciudad de Rosario, el 29/10/2017. Fruto de este encuentro los licenciados en Filosofía Patricia Alejandro (PA) y Damián Ciappina (DC) le ofrecen al lector la conversación con el filósofo, abierto tanto al diálogo, como a la escucha situada.

Agradecemos al Doctor Enrique Dussel y a los Licenciados P. Alejandro y D. Ciappina el aporte de esta entrevista a la Revista de la Escuela de Filosofía (UNR).

Silvana Carozzi

(Directora de Cuadernos Filosóficos)

Anabel Hernández

(Directora de la Escuela de Filosofía) 


\section{Entrevista}

PA: -¿En su opinión la idea de fraternidad es un concepto caduco en el mundo contemporáneo?

Dussel: -Yo comienzo a trabajar la fraternidad, a partir del concepto de tolerancia. La UNESCO declaró en 1995, el año de la tolerancia. Este concepto aparece en Locke, un pensador ligado al liberalismo.

La tolerancia implica una visión muy despectiva del otro, "aguantar al otro", dejar que sea, pero en el fondo no me interesa demasiado... un concepto muy negativo. Pensé que había que ir más allá y me encontré con unos textos impresionantes de Bartolomé de las Casas y presenté una ponencia en un Congreso Interamericano en Lima, "Mas allá de la tolerancia: el tema de la solidaridad". Luego apareció un libro de Derrida, Políticas de la amistad, en donde él intenta un diálogo sobre todo con Nietzsche y Carl Schmitt. Pero Derrida en el fondo no sale del tema, no logra formularlo...

Me propuse algo más largo, el tema de la solidaridad y lo abordé en un parágrafo del tomo tercero de la Política, ni la Historia, ni la Arquitectónica, sino la parte crítica. Sería, por decirlo muy rápido y todavía con posibilidad de muchas interpretaciones: el amor al otro como otro, más allá de la mera fraternidad, que es el amor a los otros miembros de la comunidad. Podría haber fraternidad en una comunidad de bandidos, donde todos se aman como miembros de esa comunidad, que pueden ser agresivos con respecto a los otros, pero entre ellos guardan fraternidad, es decir entre ellos pueden amarse, defenderse y ser hermanos fraternos pero como tal, la comunidad podría ser un grupo opresor.

DC: -Porque son iguales, porque hacia adentro son iguales...

Dussel: -Entre ellos iguales y con respecto a muchos otros desiguales y dominadores, por ejemplo. La solidaridad pretende plantear la superación tanto de la fraternidad como de la tolerancia. Esto surgió porque en los textos de Bartolomé de las Casas, en la cuestión de los sacrificios humanos, discutiendo con Ginés de Sepúlveda y otros, quiere refutar el argumento de que se justifica la conquista para impedir, por ejemplo, que (los aztecas) hagan sacrificios humanos porque hay víctimas, y en defensa de las víctimas, ellos hacen una guerra de conquista para que no puedan ofrecer sacrificios. Entonces Bartolomé de las Casas explica que esto no es tan automático, primero debo situarme ante el otro, teniendo pretensión de que mi posición sea universal, por ejemplo no cristiana, europea, o española. Pero, honestamente, también tengo que reconocerle al otro la pretensión universal de su verdad. En efecto, el otro tiene la convicción de que su posición es válida y tiene 
Cuadernos Filosóficos. Segunda Época, XIV, 2017

derecho a defenderla. En este sentido, por ejemplo, el sacrificio de seres humanos a sus dioses no es una mera matanza, implica ofrecer lo más sagrado a los dioses, para que la vida de esos sacrificios den la vida al sol, y este pueda darnos la vida a todos. Y esto es un argumento racional, basado en razones.

Bartolomé de las Casas dice: "los indígenas tienen todo derecho de ofrecer a sus dioses lo más sagrado: que es el ser humano, y esto no es contra el derecho natural, y se lo concede". Y después dice: "es más, si nosotros atacáramos a los indígenas violentamente actuaríamos en contra del derecho natural". Esto lo escribe en un libro que se llama Del único modo de atraer a todos los pueblos a la verdadera religión. El único modo, no es hacerle la guerra para que no puedan ofrecer los sacrificios humanos, en cambio se debería argumentar que ese sacrificio humano a sus dioses es inútil, no es necesario. Pero si yo no lograra convencerlos, porque ellos fueran todavía resistentes a mis argumentos, entonces ellos tendrían todos el derecho de seguir realizando sacrificios humanos a sus dioses. Y si yo les hiciera la guerra sin convencerlos con argumentos racionales no correspondería; esto es Jürgen Habermas avant la lettre cuatro siglos antes, cuando dice que todo consenso debe surgir como fruto de la argumentación racional. Bartolomé De las Casas está planteando esto mismo, incluso en su política el fundamento de la legitimidad es el consenso del pueblo, él utiliza la expresión “consensus populis". Es toda una política muy superior a Hobbes incluso -un siglo antes de Hobbesy democrática. Este es el primer capítulo de la Filosofía política moderna que franceses, alemanes, e incluso los latinoamericanos ignoran y consideran que en el siglo XVI la filosofía moderna nace con Descartes, cuando en realidad la Filosofía moderna surge con el antidiscurso de la modernidad de Bartolomé de las Casas, quien critica la empresa moderna como irracional, en 1514. Si yo no logro convencerlos, ellos tienen derecho a seguir haciendo sacrificios humanos y si yo les hago la guerra dice Bartolomé de las Casas- ellos tienen derecho a formar un ejército y defender con las armas su posición hasta el juicio final: ese extremo. Y esto es la prueba de que él tiene conciencia histórica de que ningún filósofo lo ha dicho anteriormente. Este es el origen de la solidaridad, el amor al otro por sobre la fraternidad española. Los amó como otros y les atribuyó el derecho a la defensa de sus propias costumbres.

PA: -Este reconocimiento del otro está mediatizado por la influencia de Levinas...

Dussel: -Reflexionando acerca de lo que Levinas llama en francés le desire metaphisique: para Levinas, meta es más allá, y phisique es lo físico, más allá del mundo, y esto es lo ético. Para Levinas lo metafísico es la ética. El deseo metafísico es la capacidad que tiene Bartolomé De las Casas de 
Cuadernos Filosóficos. Segunda Época, XIV, 2017

amar a un indio que es de otro mundo y este es exactamente el ejemplo que utiliza Levinas del deseo metafísico; de ahí se desprende toda una lógica que yo presenté en el 2005, en el centenario del nacimiento de Levinas, en un seminario que hubo en Jerusalén, en la Universidad Hebrea de Jerusalén. El tema que yo presenté era muy urticante, porque Levinas -que es un campeón filosófico de la alteridad, del otro y del amor al otro como otro- cuando habla de Israel tiene un grave problema: titubea en llamar al Palestino "el otro", tiene un corazoncito sionista y cree que el sionismo es la resolución de los problemas judíos. Yo más bien creo que es el comienzo del problema judío.

Los cristianos, que criticaban al Imperio Romano, con Constantino pasaron a fundamentar el Imperio Romano que se hizo Sacro Imperio Cristiano. Entonces, el Mesías judío que era Jesús de Nazareth, que era cien por ciento judío, que criticaba el imperio, la ley, etc., ahora es el fundamento del Imperio Bizantino, que justifica la esclavitud. Los esclavos empezaron a decir que un tal Jesús, justifica la esclavitud. Fue la inversión del cristianismo, el lío del cristianismo, que Kierkegaard denomina: "la cristiandad que negó al cristianismo".

El Judaísmo, durante veinte siglos en el exilio, pudo ser crítico de todos los sistemas, porque no tenía un Estado y no tenía un sistema. Pero desde que existe Israel empezó a justificarlo, y en vez de solucionar el problema judío justifica el Estado judío y justifica la opresión de los palestinos y entonces el sionismo y la ética de los profetas de Israel se contradicen. La cuestión era por qué Levinas no logró plantear bien el tema Palestino. Había como ochenta participantes y se hicieron dos grupos: los judíos críticos, que piensan que los Palestinos son todavía miembros plenos del Estado de Israel, y los otros Sionistas, más de derecha, que me miraban feo.

El tema de fondo es un dicho de Nietzsche que trabaja Derrida en Políticas de la Amistad, Nietszche dice: "oh amigo no hay amigo, dice el sabio ante la muerte. Oh enemigo, no hay enemigo, grito yo, el loco" (Nietzsche mismo). Este es un texto que Carl Schmitt cita y que Derrida intenta interpretar pero no sale del atolladero, no lo dice bien. El fondo es: "oh amigo no hay amigo" a partir de Aristóteles, dice éste porque un amigo perfecto es imposible... Pero eso lo dice el sabio ante la muerte. Es decir, el filósofo desde el mundo ontológico para Levinas y el sabio que ve desde el mundo, el fin del mundo. Pero el otro que dice "oh enemigos, no hay enemigos" ya no es un pensamiento helenístico-romano griego, sino que ya es un pensamiento semita, que dice "oh enemigo, no hay enemigos” ¿Por qué? Porque si yo soy hijo del faraón, mi enemigo es el esclavo que quiere liberarse, pero si amo al otro, como otro, el enemigo que es el esclavo que se me rebela y pone en cuestión mi dominación, deja de ser mi enemigo. Ahora, por la solidaridad, amo por sobre el mundo al otro y entonces ahora amo al que era antes mi enemigo.

Sucede que mis amigos tenían solidariamente por enemigos al esclavo y lo sujetaban para que no se 
Cuadernos Filosóficos. Segunda Época, XIV, 2017

liberara, porque todos vivíamos a costillas de él. Mis amigos ahora se tornan mis enemigos porque yo me hago amigo del pobre. Entonces, como el rico que de pronto se juega por el obrero y sus camaradas burgueses ahora lo toman como traidor porque está con el otro, entonces él dice: “oh enemigo, el pobre ya no es mi enemigo, ahora mis amigos, se han tornado mis enemigos y por eso soy un loco, porque me vuelvo locura del mundo en que dominaba, pero sabiduría en el mundo del otro". Y esto es lo que dice Pablo de Tarso: "la sabiduría del mundo justifica la fraternidad, pero niega la solidaridad con el otro". En cambio cuando yo amo al otro me vuelvo loco para el mundo y para mis amigos, pero tengo una nueva sabiduría y ese es el tema de la solidaridad: es el amor al otro como otro que pone en cuestión al sistema de dominación y lo abre a un mundo distinto. Y es entonces, el pasar de Egipto a la tierra prometida, donde mis amigos se tornan mis enemigos y mis enemigos se tornan mis amigos. Trabajo este tema que Derrida no descubre, pero que con la lógica de la filosofía de la liberación se entiende. "De la fraternidad a la solidaridad"* es un artículo bastante complicado, una crítica a Carl Schmitt, a Derrida y un tema de la política de la liberación, en el momento justo de cambio, en donde se critica al sistema y se abre el horizonte a un sistema futuro más justo. Este es el tema de la solidaridad.

DC: - ¿La solidaridad sería una desalienación y un alienarse en el otro? ¿Me puedo perder místicamente en el otro?

Dussel: -Alienarse es ser otro que sí mismo, no es tanto que me desalieno, cuando puedo amar al otro que es el enemigo del sistema, en tanto que es el fundamento del sistema, como el esclavo. El esclavo permite todo Egipto, pero él es el enemigo supremo en el sentido de que si se libera, se cae todo el sistema.

Un país como EE.UU donde hay una gran separación entre ricos y pobres, y además es pragmático, donde se cree según Bentham que hay que hacer un sistema ético en donde la mayoría sea feliz, el pragmatismo es peligroso, porque entonces los felices norteamericanos tienen a los pobres como su enemigo que son los que pueden poner en cuestión su riqueza y si, a su vez, forman una estructura ambiental terrible, entonces, eliminan a ese pobre porque pone en cuestión al sistema, y entonces se transforma en una civilización peligrosa para la humanidad, por querer ser feliz eliminando a aquel que ponga en peligro su felicidad, quien pueda apropiarse de sus bienes impidiéndole seguir siendo

\footnotetext{
* Dussel, E, (2005) De la Fraternidad a la Solidaridad Hacia una Política de la Liberación, México, UAM-Iz.
} 
Cuadernos Filosóficos. Segunda Época, XIV, 2017

rico. Y eso es el pobre por naturaleza, porque es quien desea cumplir los objetos de sus necesidades no cumplidas y por lo tanto aparece para el rico como codicioso de sus bienes, pero el pobre lo que quiere es poder consumir algo para no morir. Y el rico ve esto como una guerra contra ellos.

Lo que yo quiero mostrar, es que si yo me compadezco -y la solidaridad es también una compasióndel dolor del que sufre, me vuelvo traidor de mi grupo y soy considerado por mi grupo como un traidor; me vuelvo un enemigo de mis amigos.

Esta es una lógica, que sin tener en cuenta la exterioridad de la totalidad, no se puede entender ni resolver. Es una lógica de la exterioridad del sistema que asume el sufrimiento del otro, entra en una lógica de confrontación y se transforma en un loco para el sistema, porque hace lo contrario de lo que hacía antes, por eso Nietzsche dice: “oh enemigos, no hay enemigos, grito yo, el loco", y esa locura del mundo es racionalidad del pobre para que se libere. Son dos sabidurías contrarias, y es una expresión hebrea, de Pablo de Tarso, no ser expresión de la sabiduría del mundo y el mundo es el sistema dirigente. Entonces, hay que instaurar una racionalidad de la alteridad, que es locura para el mundo, pero es racional con respecto al nuevo mundo. Esta solución no logra darla Derrida, pero si logra aclararlo la filosofía de la liberación, este tema que ronda toda la obra de Derrida sin poder resolverlo y aún más, yo diría que ni siquiera Nietzsche, que lo formula, entiende bien lo que está diciendo. Es un tema complicado, si lo simplifico digo que es que el amor al dominado supera el horizonte de los valores del sistema.

PA: -¿La solidaridad, permite visibilizar al dominado? El dominado no tiene voz en el sistema, está excluido...

Dussel: -Claro, no tiene voz, o mejor, tiene voz, pero no se lo deja hablar; habla y no se lo escucha, y quiere hablar y se le tapa la boca, claro que tiene voz, pero no se lo escucha... entonces se trata de escuchar su clamor pero el sistema tiene oídos sordos... "El que tenga oídos para oír que oiga...” Pero tiene oídos para oír y no escucha nada... no escucha el clamor. En el mito del desierto, el Absoluto como criterio ético dice: "he escuchado el clamor de mi pueblo" que sufre en Egipto... Y ahora lo lanza quién se va a jugar por la liberación de ese pueblo, se va a jugar por el otro. Es una dialéctica de la voz y el oído, la palabra que se hace carne y revolución contra el sistema.

DC: -¿Cómo hacemos para restituirle al cristianismo su poder disruptor?

Dussel: -Es el tema de Walter Benjamin. Y no sólo al cristianismo, sino al judaísmo... Y no sólo a 107 
Cuadernos Filosóficos. Segunda Época, XIV, 2017

ellos, sino a la racionalidad humana, porque en el fondo estas dos tradiciones hablan del ser humano. ¿Cómo restituirlo? Poniéndose en el lugar del oprimido y escuchando su voz. Por eso mi Política termina por ser un "poder obediencial", y obediencia es ob-audire, escuchar el que tengo adelante, entonces el representante político debe tener un poder obediencial, significa: "voy a ejercer aquello que el otro me dice y yo escucho y realizo, hago algo, a su servicio". Es la definición de poder político como servicio. Eso que en griego se dice diakonía y en hebreo se dice abad es trabajo; ebed es el servidor entendido como servicio. Es el servidor de Yavhè que toma todos los sufrimientos, los acumula y relanza el sistema. El mundo mítico sirve para esclarecer una racionalidad implícita en el mito. Hernan Cohen dice que el método consiste en tomar el lugar del pobre, y desde el pobre empírico hago el diagnóstico de la patología del Estado. Es decir, critico la divinización del sistema, lo invierto y entonces el sistema ya no está fundado en sí mismo, sino que lo desfondo, le saco el fundamento y al invertirlo lo pongo al servicio de aquel a quien explotaba, que es el ciudadano de la nueva sociedad. Liberar es invertir el sistema.

DC: - ¿Y si el dominado quiere integrar el sistema? ¿Si el dominado quiere los valores del sistema, y no quiere invertir las relaciones de clase?

Dussel: -El pueblo también puede estar desorientado y puede aceptar el fetiche y en el mundo mítico también hay metáforas: los esclavos de Egipto, en el medio del desierto se construyen un dios: el becerro de oro; el pueblo lo adora y dice que en Egipto estábamos mejor, teníamos comida... El pueblo quiere rápidamente conseguir el fin y si no lo logra quiere volver a lo fácil. Por eso cae en la idolatría, cae en el fetichismo. El pueblo no se da cuenta que tiene que empezar a construir en la disciplina un nuevo sistema, hay que aprender a sufrir para construir lo nuevo.

Lula disminuye la cantidad de pobres, hace clase media de un grupo grande del pueblo y la gente ahora dice: “ya no me interesa más Lula, ahora quiero ser más rico, y quiero alguien que me de más bienes, que venga uno que me enriquezca más.” Entonces, se da cuenta que ya no tiene nada, pero que tampoco puede volver atrás... y aprende. El pueblo tiene que tener un aprendizaje porque comete errores, ahí hay una tarea pedagógica y por eso un Hugo Chávez los domingos daba clases de primaria al pueblo. "Vamos a hacer ahora un proyecto", le dice a la población, "ustedes lo van a presentar, se tienen que organizar en asambleas para acordar y decidir. No les vamos a dar nada si ustedes primero no se organizan". El pueblo quiere que el gobierno les de las cosas hechas, no quieren hacer nada, no quieren trabajar, quieren seguir como estaban. 
Los venezolanos no tienen industria; se les dio dinero para hacerlo y fue a las manos del capital privado, de las trasnacionales. Los venezolanos siguen colgados del petróleo, desde 1902, que el dictador Gómez descubrió el Petróleo. Y Chávez no logró impulsar todavía a ese pueblo para que se haga responsable de su destino. No participa, ni quiere trabajar, quiere lograr las cosas fáciles. Pero está sufriendo... Una lección de cómo empezar a construir las cosas....Entonces el pueblo puede desorientarse y cometer errores, claro, para eso la corrección magisterial o pedagógica de los grandes líderes políticos que no pueden decir: “después de cuatro años voy a ser reelegido o voy a elegir”. Claro, eso lo puede hacer Estados Unidos que tiene un sistema estable. Pero un pueblo que nunca ha participado necesita mucho tiempo de un maestro que los conduzca, "ah!... no es democrático porque lo van a reelegir", claro que no es democrática la situación, pero es necesario que un pueblo asuma su destino, no es fácil: hay que criticar también la traición que un pueblo comete consigo mismo.

No es populismo decir que el pueblo es sagrado y no se equivoca. Se equivoca, y ahora el paso atrás que ha dado Argentina... Ahora que sufra, no el más pobre que votó en contra, aún el que votó a favor, también tiene sus problemas y no creo que estén contentos con la elección...Toca entonces, comprender y analizar qué pasó, así es la historia, se va aprendiendo de a poco. Tiene que haber alguien que tome el relevo y haga algo mejor. No es fácil, hay que formarlo...

D.C.: -Ahí yo pensaba, el mandar obedeciendo de Chiapas es posible porque existe un núcleo éticomítico ontológico fuerte de la sociedad maya. Pero pienso en la sociedad capitalista donde los lazos se rompen, hay individualismo ¿Cómo poder restituir una comunidad para construir ese común? Está bien, por el sufrimiento...

\section{Dussel: -Claro.}

D.C.: ¿¿Hay que pensar una pedagogía cívica? ¿Allí está el rol del filósofo, que tiene que estar marcando un lugar, además del líder?

Dussel: -Muchas cosas simultáneas y muy difíciles. Algunos piensan que cambiando las instituciones y poniendo en común, en manos del Estado, los medios de producción ya tocamos el reino de los cielos. La subjetividad no cambió nada, era tan individualista como antes, tan moderna, y entonces no hubo cambio de la subjetividad, la gente quiso consumir más de lo mismo. Yo viví una experiencia brutal, fui más de una vez a Cuba y soy solidario con la revolución. Pero viví en una casa de una familia donde el hijo estaba cortando cañas, solidario con la revolución, un militante. Dormí en su 
Cuadernos Filosóficos. Segunda Época, XIV, 2017

cama, miré al techo y no se imaginan, todo forrado de recortes de revistas, como cien fotografías. Las paredes no, el techo. Lo que quiere decir que cuando estaba acostado, lo estaba mirando; ¿y qué era eso?. Todos los objetos de la sociedad capitalista, un celular, un zapato, una corbata, todos los bienes que no tenía en Cuba; y era un militante. Pero su deseo era consumir lo que vendía el mercado. Yo digo, esa subjetividad no ha cambiado un milímetro, habría que cambiar también el modo del consumo y tener otra subjetividad. Pero como se arrastró en muchas cosas un materialismo simplista, también se arrastró la posibilidad de construir nuevas subjetividades; eso no se hace ni en un año ni en diez, se necesitan cincuenta años o un siglo. Entonces de pronto, ¿dónde están los ministros afros de Cuba? ¿Usted ha visto alguna autoridad cubana negra? Todos blanquitos y el cincuenta por ciento del pueblo es negro. Dicen: “el pueblo cubano no es católico, no tienen religión” ¿Cómo que no? ¿Y el culto a los que ellos llaman santos? Es popular... todo el mundo cultiva una religión. No es católico, pero es una religión. Y dicen que no, ¿cómo que no? Entonces hubo una cierta ortodoxia que minimizó el cambio y creyó que con el cambio de cuatro o cinco estructuras económicas hacíamos la revolución... No, eso necesita más tiempo, la subjetividad, la objetividad y además una nueva política que no debería ser burocrática ni del partido, sino participativa. No era como lo pensaba, todo era mucho más grave y se vuelve atrás de inmediato. Mire a los rusos: están volviendo al neoliberalismo. ¿Cuánto tiempo pasó? ¡Setenta años!... y ni siquiera han hecho un diagnostico de lo que pasó.Yo digo que está faltando una crítica de Marx al socialismo real, está faltando una crítica marxista del marxismo leninista tradicional. Uno dice, es muy pesada la cosa, sobre todo porque el capital no solamente tiene estructura, sino que tiene cultura y fomenta los deseos; el inconsciente y los objetos no sólo son mercancías, sino que producen la subjetividad. Esto hay que superarlo con una ética y demás.

Los medios, la mediocracia es tremenda y están en manos transnacionales. En la Argentina se quiso hacer una ley de medios y Clarín la echó abajo y triunfó. Y entonces se habla de democracia, y Estados Unidos dice que ahora sí hay democracia; no hay ninguna porque hay monopolio de los medios de comunicación y el pueblo traga eso ingenuamente. La tarea es ingente.

DC: -Tragan ingenuamente cosas, pero también hay tradiciones que explotan, como el racismo, muy explícito, la sociedad argentina es muy racista.

Dussel: -Hubo racismos desde el comienzo de la Modernidad, desde 1492, porque antes era distinto. En la Modernidad el racismo es la clasificación social de las personas, no por clases sociales, sino 
por razas. Y eso ha calado hasta en las personas de color, que también se sienten minusválidos; aceptan al racismo atribuyéndolo a que "Dios lo ha querido" y lo deben soportar como un mal sin lograr superar el susto. Lo mismo el machismo y todos estos "ismos" que limitan la subjetividad. Por eso la liberación es a muchos niveles no sólo una economía anticapitalista o una política antiliberal. Tiene que ser una afirmación del género antimachista, contra el racismo de la raza blanca y la cultura eurocéntrica. Y uno piensa ¿cómo haremos eso? Y bueno, la iremos haciendo de a poco o moriremos. Y también la humanidad puede desaparecer si no se toman las cosas en serio; por de pronto hay que ver y hacer un diagnóstico con espíritu crítico. Saber cosas que no sabíamos, porque ingenuamente estábamos reproduciendo la dominación. Y allí la descolonización.

DC: -Yo trabajo con adolescentes, en una escuela secundaria de periferia. Trabajo con chicos de tres barrios diferentes, uno de clase media/media baja, uno pobre, y una villa. Uno ve la lógica de desprecio en cadena, donde el blanco de clase media ve al mestizo, al morocho, al "negro de mierda", como les dicen, y después el otro desprecia al del otro barrio más pobre y por útimo queda el indígena. Entonces uno ve la cadena de desprecio y hay que hacer una ruptura de estructuras mentales para poder modificar eso; coincido que es a muy largo plazo.

Dussel: -Es también dirigido por el sistema y exacerbado por el sistema. A largo plazo, o no tan largo plazo. Porque esto va cumpliendo etapas cada vez más graves. Es como la ecología, vamos tomando conciencia de que esto no va a durar mucho. La catástrofe se mide en pocos decenios, entonces se va a empezar a sufrir en serio ciertas cosas. La humanidad va a tener que tomar decisiones que nunca antes hubiera pensado y aun los dominadores van a sufrir las consecuencias. Pero hay que ir estudiando, formulando y mostrando los principios éticos que pueden evitar eso. Pero no valores, virtudes, cositas.... Tiene que ser una ética de la vida. Y si usted no apoya la vida, va a ser de muerte. Tiene que ser una ética dura, más dura que la ciencia y que la experiencia empírica. No la frutera después de la comida o el whisky al final, no. El plato fuerte es la ética. Entonces tenemos gran responsabilidad los pensadores para mostrar lo que está pasando, pero en fin...

P.A.: -¿Qué políticas cree que debemos promover los que trabajamos con adolecentes o estudiantes universitarios contra la idea de que no se puede contra el sistema. Hay como una idea generalizada en el alumno de que las cosas están dadas, que el sistema es así y van a seguir siendo así?

Dussel: -Ellos han logrado formular una teoría de la no alternativa y la imponen desde el apoyo militar 
Cuadernos Filosóficos. Segunda Época, XIV, 2017

a esa idea, el apoyo a todas las riquezas de las transnacionales, que es inmensa; todo el sistema apoya esa ideología y domestica a todo el pueblo y lo tiene ahí. Pero eso no funciona, la pobreza crece, la gente sufre, entonces habrá que hacer un contradiscurso débil, pero la debilidad se va a volver, en cierto momento, fuerte. La crisis va a aumentar y es necesario preparar ese momento. Hay que trabajarlo, porque llegará el momento en que, por la presencia de las redes, la televisión y demás medios dejarán de ser vistos. La gente se tendrá que levantar, no hay otra. Y si no se levanta, el homo sapiens va a desaparecer, quedarán cucarachas y ratones, porque esto va a la muerte total. Si sube la temperatura y se empiezan a ver los efectos ecológicos que se prevén, el fin de la vida humana ciertamente será primero. Hay otras vidas, animal y vegetal que van a resistir mucho tiempo y que van a necesitar millones de años para recomponer la tierra, porque como vamos nos tenemos que volver un tanto catastróficos. Como dice Walter Benjamin "mete freno", no digamos "sigamos creciendo", "hemos vendido más autos estamos bien", "hemos aumentado el 5\% la producción, estamos mejor"... estamos peor que nunca. Nos cavamos la fosa. Y para eso hay que romper toda la ideología del sistema.

D.C.: -¿No sería necesaria la catástrofe para poder hacerlo?

Dussel: -Es que se va a producir. Ciertamente la catástrofe ya ha empezado y está muy avanzada. Lo que pasa es que no nos damos cuenta a qué nivel. Se están derritiendo los grandes glaciares de la Antártida. Están rompiendo el hilo de la refrigeradora y va aumentar la temperatura. Va a comenzar a morir el plancton y vamos a tener un cambio de clima feroz y va a aumentar el ozono, va a haber cambios en que la humanidad va a entrar en una situación verdaderamente trágica. Tomarán las medidas que debieron tomar antes y tardará miles de años para recomponer lo que estamos haciendo. Pero el capital no tiene capacidad en su lógica de tomar esa decisión, tiene que desaparecer. La irracionalidad de Trump muestra que es capaz de hacer suicidar el capitalismo y la humanidad, antes de dar las órdenes contrarias. Cada vez es más rica menos gente y más gente se va a ir empobreciendo; entonces llegará un momento en que van a tener que cambiar las cosas. No se trata sólo de nuestros pobres, son los pobres de Estados Unidos, de Alemania y la misma clase media que comienza a tener situaciones ecológicas cada vez más difíciles.

Para mí, lo ecológico es uno de los elementos fundamentales, pero hay otros. Justamente hay que hacer diagnósticos de esas negatividades en filosofía y no estar hablando bobadas, como hace a veces la filosofía. 
Cuadernos Filosóficos. Segunda Época, XIV, 2017

D.C.: -Dice usted que con Bartolomé de las Casas nace la filosofía moderna como primer antidiscurso, entonces ¿la filosofía, para ser filosofía tiene que ser antidiscurso necesariamente, no puede haber filosofía conservadora?

Dussel: -Siempre hay y siempre ha habido una filosofía conservadora que funciona en épocas que yo llamaría clásicas. Por ejemplo, lo divido en dos momentos: momento a) creativo, de un sistema en todos los niveles: estético, político, en el que se crean nuevas estructuras, se solucionan muchas injusticias del sistema que quedó atrás y la humanidad transcurre una etapa creativa. Y momento b) conservador, en el que las cosas funcionan, hay consenso, la clase dirigente es dirigente y las cosas marchan, pero empiezan a entrar en crisis. Y en el momento agónico, las cosas ya no marchan. Gramsci dice que, cuando la clase dirigente pierde el consenso, o cuando crece el disenso, la función de la filosofía crítica es mostrar la verdad del disenso y hacerlo más radical y más coherente. Cuando pierde el consenso, o crece el disenso la clase dirigente se transforma en clase dominante, es decir, represora de los que empiezan a sufrir los efectos de la crisis. En fin, o se hace una reforma parcial y se emparcha todo el sistema, o surge una nueva etapa histórica con otros supuestos. Yo creo que estamos al fin de la Modernidad, no solamente del capitalismo. Y lo estamos viendo, no hay que inventar nada. Puede durar hasta fines del siglo XXI . Esto no marcha como sigue, porque los retoques que se están haciendo son insuficientes y no hay quien tome las decisiones, nadie pude atacar la crisis ecológica de frente. Se opta por retoques secundarios pero la caída a pique del avión va a llegar a un punto en que tocará tierra. Estamos viviendo ese momento crítico y la filosofía tiene que advertirlo, es el problema ético de la vida y la muerte. Y allí el interés por Walter Benjamin, que, repito, dice que el asunto no es hablar de progreso, sino que es necesario poner freno y ver cómo vamos a vivir de otra manera, subjetiva y objetivamente. En vez de poder consumir más, empezar a consumir lo necesario y lo que es saludable para el cuerpo humano, consumiendo la menor cantidad de energía y materia, casi como un monje, comenzar a transformarlo en un ideal del futuro de la humanidad: comer menos, comer disciplinadamente. Una casa grande ¿para qué?. Chica, normal, útil, que pueda limpiarla y donde yo pueda empezar a cambiar la subjetividad.

D.C.: ¿ ¿Hay que redirigir al deseo?

Dussel: -El capitalismo no da para eso. El capitalismo está basado en un infinito desarrollo de la producción. Pero nunca había considerado que eso significaba destruir las condiciones de reproducción de la vida. Creyó que la tierra era infinita en sus recursos. El propio Marx, que dice 
que el capital destruye a la humanidad y a la naturaleza, no veía lo trágico que era ni lo inminente que era eso, porque no había prospectivas de miles de variantes, en las que se viese la crisis ecológica que el capital produce. Entonces el problema de la ecología no es un problema tecnológico, es un problema de la esencia del capital; consiste en el nivel del plusvalor relativo al nivel de la competencia. Es decir, un capital compite contra otro para producir una mercancía a menor precio, a menor valor, y eso lo logra el que tiene mejor tecnología. Entonces tener mejor tecnología es la vida del capital porque el que lo logra liquida a los otros capitales y se abre monopólicamente por un tiempo, porque los otros no tienen ese descubrimiento. Pero cuando lo imitan, la competencia vuelve a empatarse, e inventa otra cosa. Pero esa tecnología no puede ser pensada según el criterio vida/muerte ni ecológicamente, porque eso supone el largo plazo y la competencia es día a día. O "usted mejore ahora, este año, su tecnología o el próximo la Chevrolet liquida a la Ford", y no hay vuelta. Entonces usted usa la tecnología que sea, aunque queme la materia no renovable más importante que es el petróleo. Y lo quema, lo que es brutal, porque es como quemar diamantes, es como hacer una fogata con dólares para calentar el café, es una barbaridad y lo hacemos porque es lo que permite competir. La cuestión no es la tecnología antiecológica, es el criterio de subsunción de la tecnología en el proceso de producción y eso es el capital cuya racionalidad es el aumento de la tasa de ganancia formal y cuantitativa, la vida no importa. Por aumentar la ganancia mato, y si no lo hago tengo una crisis económica. Bush dijo explícitamente que no quería entrar en una crisis económica en los Estados Unidos firmando el tratado de Kyoto, porque eso provocaba una crisis económica en los Estados Unidos, y él en cuatro años quería que la cosa marche a corto plazo. Todo política cortoplacista. Y habría que decir el proyecto de lo que vamos a hacer en los próximos mil años, no en los próximos cuatro. Y si hay un fin del mundo, que se arregle el que viene, ya cumplí, me robé lo que pude y triunfé... eso es lo irracional. En esa irracionalidad está dado todo, la ciencia tan racional se ha vuelto irracional, descubre cosas y cuando interviene en la realidad no sabe sus efectos negativos a largo plazo, mete el dedo y no sabe si una transformación genética va a destruir toda la agricultura, lo piensa en los próximos meses, en los próximos años, pero ¿qué va a pasar en doscientos años? No se tiene idea ni se propone tenerla. Eso es lo raro. Estamos, como dice Hinkelammert, en un sistema de racionalidad que es irracional, porque la única racionalidad que debería justificarse es el aumento cualitativo de la vida y eso no está en ninguno de los parámetros evaluativos de nadie.

D.C.: -¿Qué ocurre con China y sus estándares de producción y uso de recursos, que supuestamente no tiene un orden capitalista, o por lo menos tiene una lógica diferente, como dijo usted, "capitalista 
confuciana"?

Dussel: -Una meritocracia confuciana. No es capitalismo ortodoxo, es otra cosa. Tiene todavía mucho de lo moderno y en eso debe recuperar su visión más neoconfuciana, que tenía más presencia de la vida, pero en fin, eso es otra cosa. Esos son problemas de la filosofía, eso es ética, Por eso mi ética, mi política y todo lo demás es una ética de la vida, pero no de los derechistas que dicen "la vida es sagrada" y entonces no hay que cometer el aborto, y luego ignoran al nacido que sea un pobre miserable que se muere dentro del capitalismo, sin darse cuenta que la vida está detrás de la economía, porque allí no saben cómo funciona. En fin, hay temas importantes y el filósofo con esto se hace absolutamente imprescindible para la humanidad. Es la racionalidad más dura, y la matemática, la física, y todas las demás son ciencias blandas, ni saben para qué están actuando. Están inventando fármacos para solucionar una enfermedad, pero ni saben el sentido de la enfermedad, ni saben lo qué es la vida. No es asunto de volver al Neolítico, no, es escoger entre los grandes descubrimientos científicos y tecnológicos los que puedan ser reconducidos a una humanidad que tenga capacidad de superar esta crisis espantosa con la que nos estamos enfrentando por primera vez en la historia de la humanidad. Por eso Hans Jonas dice la humanidad nunca antes había pensado en el futuro, ahora realmente las víctimas son un nuevo tipo de víctimas: son las generaciones futuras. Nunca habíamos pensado eso, ahora son las victimas más brutales porque van a vivir un mundo invivible, le vamos a dejar la tierra destruida y entonces muchos dicen "yo viviré mi vidita y me moriré y todavía las cosas aguantan" ¿Y los que vengan? Les he dejado una tierra hecha un basurero y de basuras atómicas que no van a poder mandar a la Luna, la van a tener que guardar en la Tierra, porque la basura atómica no se puede mandar a otro lado. Y entonces las ilusiones de que vamos a ir a otro planeta y encontrar otros seres vivientes..., los lugares más cercanos en que podría vida quedan como a un millón de años luz y necesitamos millones de años para llegar con unos buenos cohetes. Estamos en la tierra inevitablemente para siempre, por eso digo yo, con algo de claustrofobia: la tierra se ha hecho chica y la estamos destruyendo.

D.C.: -Un sentimiento puramente moderno.

Dussel: -Sí, pero la Modernidad es una manera de haber descalificado la naturaleza. Le ha sacado la cualidad, queda la cantidad abstracta, y en pos de esa concepción de la naturaleza estamos destruyendo las condiciones de la vida en general y la de la vida humana. 
Cuadernos Filosóficos. Segunda Época, XIV, 2017

D.C.: -Es el ideal de Francis Bacon: hay que dominar a la naturaleza.

Dussel: -Bacon está en el origen de ese problema, porque ellos con la ciencia empírica y la tecnología quisieron dominar la naturaleza, explotarla, total, decían..., es naturaleza. Pero la naturaleza se nos vuelve -"bueno me explotas, yo te mato"- porque impides la posibilidad. Entonces hay que volverse un poco trágico para que se tomen en serio las cosas, y si no, la humanidad desaparecerá.

D.C.: -¿Hay que ser mesiánico o profético, o ambas cosas?

Dussel: -Claro, pero ahora ya no es "proletarios del mundo, uníos", sino: seres vivientes, uníos. Porque si no van a quedar todos muertos.

P.A.: - ¿Si tuviera que dar un mensaje a los jóvenes estudiantes de filosofía que les diría?

Dussel: -Lo que digo todos los días, ellos tienen que empezar a pensar nuestra realidad y realmente descolonizarse mentalmente; no lo podrán hacer de inmediato pero aprendan de los que estamos empezando a dar unos pasos creativos. Filosofía ahora, como dice Carlos Perera, es "sucursalidad", tenemos una sucursal de Coca-Cola, una sucursal de Kant, de Hegel y hasta de Marx, y entonces somos sucursaleros, distribuidores de una verdad descubierta por Europa y Estados Unidos, en Europa y Estados Unidos y para Europa y los Estados Unidos, no para nosotros. Además de que distribuimos Coca-Cola, se nos enferma. Entonces, dejemos de ser sucursales y hagamos un buen jugo de naranja que es más nutritivo, y nosotros podemos exprimirlo y no dependemos de una fórmula misteriosa por la cual hay que pagar royalties. Hay que realizar una inversión y la inversión es pensar lo nuestro. ¿Cómo? Vean lo que estamos haciendo, lo nuestro es “como se piensa lo nuestro”. En Estados Unidos hay una sola filosofía que nació en Estados Unidos: el pragmatismo, todo lo demás fue mejorar, empeorar corrientes europeas hasta el pensamiento analítico del Círculo de Viena, pero han crecido. Yo humildemente dije: la única filosofía de origen latinoamericano es la filosofía de la liberación. Cuando me pregunta usted ¿qué filosofía practica? La de la filosofía de la liberación, ¿dónde nació?, en América Latina. Qué, ¿no comenta ningún autor europeo? No, usamos todo lo que se encuentra, pero no es ecléctico, nos da pautas pero partiendo de nuestra realidad y eso nos sirve para interpretar. Pero viene un levinasiano y dice "Dussel no interpreta bien a Levinas, ha confundido la exterioridad del otro que en Levinas es abstracta y la aplica a América Latina, allí comete un error”. No es un error, yo tomé Levinas, lo apliqué al nivel concreto que Levinas no lo hizo, y algunos dicen “está más 
Cuadernos Filosóficos. Segunda Época, XIV, 2017

interesante que Levinas". Yo no soy levinasiano, uso a Levinas como un instrumento para pensar lo mío; digo "campo práctico", lo que Bourdieu llama "campo", pero cuidado no es Bourdieu, es otra cosa. El mundo como dice Heidegger me sirve pero no es lo que dice Heidegger, y así todos. Pensamos ya desde nosotros, ¿Qué no es posible? Bueno, mire intente pensar la realidad y luego de un tiempo veamos qué hace usted y que hicimos nosotros, esto es perseverar. Había un tiempo en que sufría que nos ignoraran, que digan "eso no es filosofía", y me he convencido que no es así, los que me dijeron eso no han hecho nada y en último caso han recibido un aprecio del maestro que comentan en Europa, que dicen "a ver, hasta un argentino repite lo que yo digo y lo entiende, lo entiende bien", como diciendo "un bárbaro". Yo no repito, me animo a decirle que usted no tiene razón y es eurocéntrico. Prefiero equivocarme en ese juicio que intentar imitarlo simplemente, eso sería el error total. Ser un buen habermasiano no sirve para nada, continuar a Habermas desde nosotros y surgir desde otro horizonte y utilizar Habermas para cosas nuestras eso sí sirve. Por eso debo saber bien Habermas, tengo que aprenderlo, estudiarlo sabiamente, pero con el método de Habermas más allá de Habermas, con Nietzsche más allá de Nietzsche, con Levinas más allá de Levinas; ¿Y de dónde más allá? Desde lo nuestro. Y lo nuestro muchas veces es más popular, nuestros sabios populares. La gente en su sufrimiento también tiene sabiduría. Entonces yo a un indígena lo tomo muy en serio. 